\title{
Making Languages an Object of Public Policy
}

\section{Joseph Lo Bianco}

$\mathrm{T}$ This article explores key issues involved in making language an object of public policy with particular reference to the relation between the multilingual competence of Australians and the perceived national need for competence in the languages of key trading partners. The theoretical framework that dominates in this field of making policy around language issues emerges from applied linguistics and sociolinguistics and is generally known as language planning. These branches of scholarship locate the systematic study of language within either a pedagogical framework or a sociologically oriented framework (Kaplan and Widdowson, 1992). Within these frameworks many language planning scholars locate the practice of public policy making on languages under three broad categories. 'Status planning', which addresses the relative position and role of different languages (or varieties of a single language) within a single administrative or political unit. 'Corpus planning', which involves technical work to the internal resources of a language (its words, grammar, sounds, writing system etc.) usually aimed at permitting the target language to handle technical or advanced scientific discourse. Finally, 'acquisition planning' which refers to the policies that public authorities adopt towards the learning and use of new languages or of new forms of language (Cooper, 1989). This article concerns itself only with aspects of status and acquisition planning in the Australian context.

The range of specific issues of language taken up within explicit policy determinations is extremely vast and involves both multilingual societies and 'monolingual' societies. Monolingual societies, or societies in which minority languages are very marginal to public life, tend to evolve policies around questions of language style, accent, pronunciation (even spelling and writing conventions) and these can become the object of debate and contest. However, explicit policies on language are more typically found in multilingual societies the great majority of the world's societies are multilingual and face more challenges in developing languages policies (Edwards, 1994).

A problem arises when there is a perceived mismatch between what might be called the existing domestic language resources and the language skills perceived to be needed by a society. Such a problem is highly relevant to Australia's language policy making. Much recent policy making in Australia has been driven by the idea that the bulk of Australia's bilingualism is contained within immigrant communities and is perceived by government to be different from the languages

Joseph Lo Bianco is the Chief Executive of Language Australia: The National Languages and Literacy Institute of Australia 
dictated by Australian economic, geo-political and strategic interests (Ozolins, 1993; Djite, 1994; Clyne, 1991b; Lo Bianco, 1990).

There is a perception that much of Australia's bilingualism is in European languages and Australia's economic and political interests favour the Asian region (Sheridan, 1995; Irwin, 1996; Lo Bianco, 1996; Byrnes, 1994). There also appears to be a considerable reluctance in public policy to favour the cultivation of minority languages as a skill even when these coincide with the languages of trading partners. Furthermore, there appears to be a tendency to conceive of such domestic language skills as an obstacle to English (Lo Bianco, 2000) such that planning to overcome perceived gaps in national language capability favours new learning of key languages by English speakers rather than the cultivation of existing potential among minority communities (NBEET, 1996; Cope and Kalantzis, 1997).

An overview of the phases and features of Australian language planning, both deliberate and implicit, will help illustrate some issues that arise when public authorities make language an object of policy.

\section{Australia's Language Planning}

For most of Australia's national history language planning and policy making has been indirect rather than explicit - driven by the implications for languages of decisions taken in other fields. Language policy of this kind is submerged within more general policies in education, immigration selection, foreign trade patterns and relationships and needs to be extracted from these other fields of endeavour. Despite this difficulty the effects on 'languages' of wider policies do suggest a consistent pattern of Australian language planning. Its overarching historical goal has been for English monolingualism modelled on Southern British forms of speech (Ozolins, 1993; Djite, 1994) although Australia has always been a polyethnic and linguistically diverse society (Clyne, 1991a).

This overarching goal is a result of the collective force of informal language planning as implied in decisions and measures taken in related fields over a long period of time combined with prevailing public attitudes and some instances of explicit language policy.

The four principal means for promoting this goal of English monolingualism, both formally and informally, have been:

- Stigmatisation of Australian forms of English and the privileging of Southern British norms of pronunciation and expression.

- The repression of Aboriginal languages through the forced separation of families, the aggregation of different language speakers so that English based creole contact language forms or pidgins emerged to facilitate communication, and the banning of the use of indigenous languages in schools.

- The marginalisation of immigrant languages. 
- The trivialisation of foreign language study in general and making bilingualism a very uncommon achievement (Lo Bianco, 1990).

During the First World War several Australian states introduced legislative amendments to their education acts to ban the teaching in languages other than English, or to force schools teaching in other languages to convert to English-only instruction. The majority of these programs were in German. Ordinances to deGermanise the name of towns in the Western districts of Victoria and parts of South Australia also occurred at this time (Smolicz, 1994; Selleck, 1980).

\section{Ideologies of Language Planning}

Since the late 1960 s the following four main constructions of the language and policy connection have jostled for public appreciation. In debate and in actual policy texts on languages these four ideologies of language and its wider connection to the sense of the Australian nation have influenced both acquisition and status planning. These have broadly been a linguistic correlate of wider assimilationist pressure stressing British attachments, a reaction advocating pluralism divided into one version stressing Australianism and another multiculturalism, and a later pattern stressing the Asian context of Australia. While the periodisation which follows is approximate the alternatives used by other scholars are broadly consonant (Djite, 1994:6-10). Minority languages shifted from being regarded as a problem, to being advocated as a right, to being construed as a resource, with a recent return to a problem orientation (see Ruiz, (1984) for language planning orientations).

\section{British oriented Anglo-conformity.}

Policies that aimed for cultural homogenisation, requiring abandonment by immigrants and indigenous Australians of distinctive linguistic and cultural patterns were the norm until the mid-1970s (Cahill, 1996). Although the assimilative goal was not always explicitly expressed it is discernible as the underlying objective of policies as diverse as education, health, policing and law, and it characterised the mainstream sections of the community in some ways. Foreign languages policy tended to reflect inherited language choices more appropriate to Britain than to Australia while the models of English that were propagated in education and in the media ranked Australian norms low compared to British equivalents (Ozolins, 1993; Djite, 1994).

In relation to minority languages the underlying orientation of policy was to regard language diversity as a problem for teachers trying to teach English to minority language children or for children as they attempted to fit into schooling. Basing policies on this kind of operating assumption tends to bias the policy goals towards an eradication of the problem and therefore towards a replacement of children's languages with the school's English - supplanting children's language of culture, socialisation and intellectual development with the language of the 
dominant society. Although the stress was very much on the acquisition of English, there was strong policy opposition to providing specialist English services believing these to be an inappropriate intervention (Cahill, 1996).

\section{Australian models and a rights oriented multiculturalism}

The early 1970s saw the beginnings of a two part reaction to a British oriented assimilation in language. The first part was to replace British identification with Australian alternatives. Although evolving for more than a century the idea that local linguistic norms were the appropriate models for educational practice in Australia became widespread at this time. These changes were influenced by the 'Australianist' cultural politics of the Whitlam era; the reaction against Australian involvement in Vietnam and, therefore, the assertion of independent modes of thinking about national culture; and a reaction to Britain's accession to the (then) European Economic Community. These developments accompanied and reinforced the beginnings of appreciation of wider cultural diversity, with immigrant and indigenous components, as constituting a new national identity potential for Australia.

Policies developed around this time, as well as reports of public enquiries into immigrant and Aboriginal children's education, reveal two basic ideologies and orientations to diversity of language and culture. The first continues the 'problem' mode, but instead of seeking to replace the first language it seeks to offer specialised language (English as a second language) and culture retention programs. The second is to move from regarding diversity as a problem to advocating the retention of minority language and culture as a 'right'. Reports of this time started to reflect this idea that in a new kind of Australia, one in which national identity itself was being negotiated, minorities had a right, as citizens, to seek to be reflected in the institutions of the nation. Language and cultural retention, while learning and adopting English as the common national language, were seen to be a right that benefited the individual and the community (Djite, 1994; Ozolins, 1993).

From the late 1970 s to the mid-1980s, it was clear that acquisition and status planning were aiming at national bilingualism with minorities acquiring English and the majority acquiring a second language. This complementary pattern infuses much of the policy discourse of the period and gives effect to a status change for languages in general.

\section{Culturally oriented multiculturalism}

Gradually the advocacy of rights to the maintenance of minority cultures and languages waned. A key reason for this was the realisation that the actual retention of minority languages and cultures rests largely with individual communities, and that public institutions have little scope for direct, practical intervention to support all differences of language and culture. A new manner of thinking emerged. This regarded language and cultural retention as a 'resource' 
rather than a 'right' and was accompanied by a shift in public policy towards notions of cultural diversity for all rather than minority language rights. A right involves sanction against some authority for non-compliance. A resource involves thinking about the benefits (intellectual, cultural, economic and social) of assisting young people to retain and develop a mastery of the language of their families, and the cultural knowledge that they are developing in their communities (Lo Bianco, 1990; Clyne, 1991a; Moore, 1996).

\section{Economically motivated Asia-literacy}

An altogether new force emerged by the late 1970 s that ultimately came to be known by the term Asia-literacy. To a large degree, this reflected a reorientation of trade policies caused by reductions in Australian exports to Britain and the need for the nation to secure new markets for its produce and raw materials. Inevitably, the new market prospects were in the geographically closer Asia-Pacific zone that was undergoing rapid economic development.

This economic imperative combined with geo-political and strategic interests in elevating interest in bilateral and multilateral relationships with Asian countries. From the early 1980s onward, and more strongly during the early 1990s, as the focus shifted from community orientations to national economic and strategic considerations, public policy discourse and many reports of enquiries advocated strongly the teaching of a selected number of key Asian languages (Sheridan, 1995; Irwin, 1996; Lo Bianco, 1996; Byrnes, 1994). These were advocated not principally as skills that Asian Australians could contribute to the body politic of Australia, but rather as new learning that English-speaking Australians would undertake (Ozolins, 1993; Clyne, 1991b).

As a result of these developments, status planning for minority languages was challenged and a circumscribed role for such languages, including indigenous ones, was advocated while acquisition planning for foreign prestige Asian languages experienced a period of vitality that was wholly new in Australia.

\section{National Policy}

The period between 1987 (when Australia adopted the first explicit policy directed at language) and 1994 was one of intense policy development. Commonwealth and state governments issued policy statements in regular succession (Djite, 1994). The idea that language was an appropriate object of education, health and other kinds of policy domains became widely accepted. Indeed, states and territories, as well as local authorities, began to compete with each other about the priorities, the underlying ideologies and the resources devoted to, language policy issues.

At the Federal level the main explicit policies were:

- National Policy on Languages (NPL) (Lo Bianco, 1987).

- Australian Language and Literacy Policy (ALLP) (DEET, 1991). 
- National Asian Languages and Studies in Australian Schools (NALSAS) (COAG, 1994).

To a large extent the NPL culminated the phases of pluralistically oriented language policy of the 1970s and 1980s whereas the ALLP and NALSAS have contained different and even opposing emphases. In the late 1990s, language policy appears to have returned to an earlier pattern that ranks English, and English literacy not as complementary to other languages (aiming, therefore, for bilingualism) but considers language diversity as a problem. The concern that recurs prominently in policy this time is for English literacy standards. The effect of this strong and insistent advocacy of the priority of English is to make vulnerable many of the extensive achievements that Australian education has made for multicultural and multilingual education (Freebody, 1997, 1998; Miller, 1999; Herriman, 1996; Nichols, 1999; Moore, 1996).

\section{0s policy}

The 1980s can be seen as a decade of coalition building around pluralism as a basis for national language policy that eventually culminated in the Commonwealth Cabinet's endorsement of the National Policy on Languages on 4 June 1987. The concept of pluralism had been a growing and powerful policy theme throughout the 1970s and 1980s. For much of that time pluralism understood initially in the more limited sense of 'ethnic-based multiculturalism' but expanded subsequently to incorporate a wider sense of Australian diversity comprising indigenous pluralism and diversity within mainstream Australia became a powerful political constituency.

However, it was not until the 1978 Fraser Government sponsored review of post-arrival services and programs (Galbally Report, 1978) that the notion of pluralism representing a basis for social policy in Australia became accepted. The Fraser Government introduced and endorsed its own version of multiculturalism (which had previously been principally a Labor Party project) thereby universalising cultural diversity as a national endeavour (Cope and Kalantzis, 1997). Labor had conceived of multiculturalism principally as an embellishment of class differences in society. In 1989, via the adoption by the Hawke Government and the acceptance by the Liberal opposition of three principles in the National Agenda for a Multicultural Australia (economic efficiency, cultural identity and social justice) (OMA, 1989), Australia achieved a rare cross-political compromise on a vexed social issue.

This unique phase in Australian social planning was inaugurated by the Fraser Government's legitimisation of official multiculturalism/multilingualism. Specifically the Galbally Report focussed on funding for migrant settlement programs, and especially for English as a second language. However, it also opened the door to other languages, established the Special Broadcasting Service provided financial assistance to ethnic schools. Its style was consultative in preparation and implementation. It represented a decentralised style of policy 
determination that characterised more directly the language oriented policy developments of the 1980s. The NPL in many ways was the language articulation of this wider multicultural accommodation in Australian political culture (Moore, 1996; Djite, 1994). However, both Labor and Liberal parties have retreated from pluralist principles in the 1990s.

\section{NPL and ALLP}

Along with the NPL the Australian Language and Literacy Policy is the other national language policy text in Australia that aims to produce a comprehensive coverage of the field. Although they are very different from each other (in both substance and style) the ALLP explicitly claimed to be derived from and closely influenced by the NPL (DEET, 1991).

The ALLP represented itself and claimed to be a continuation of the NPL. This claim was intended to forestall the energetic public criticism that had been waged against its introduction. However, in the reality of its essential ethos and objectives the ALLP contradicted and sought to undermine the core multicultural and multilingual basis of the NPL and especially to disenfranchise the coalition of community-based interests that had brought it about. Many commentators note that, despite its self professed claims to continue $1980 \mathrm{~s}$ collaborative determination of policy and to retain the broad scope of the NPL, the ALLP in fact stresses earlier models of central determination. It also prefigures later emphases on language skills, and problems, rather than language rights and resources (Moore, 1996; Herriman, 1996; Djite, 1994), and has a more restricted focus (Ingram, 1994).

In her detailed comparison of the differences between these policy texts Helen Moore (1996:480) observes:

The ALLP 'Foregrounds English' and 'Asian' languages; ties English literacy to education, training and employment; views not 'speaking' English as a threat to democracy; ties Asian languages to trade ... generalises and obscures the role of different languages by mythologising the instrumental value of some, obliterating others, and demonising the consequences of lack of English.

These characteristics are contrasted with the NPL which:

Articulates the multiple values for languages; focuses on the potential of languages as resources in a variety of ways.

These differences are the systematic effect of applying central, elite determined language restrictionism to a pluralist conception of national language policy. 


\section{NALSAS and Commonwealth literacy policy}

Since the ALLP there has been a further statement that can be called a national language policy. This was issued in February 1994 and is entitled National Asian Languages and Studies for Australian Schools Strategy (NALSAS). NALSAS was derived from a report (Asia and Australia's Economic Future) of a committee chaired by K. Rudd, then head of the Queensland Premier's Department. The Strategy was endorsed in February 1994 at a meeting of the Council of Australian Governments. The key feature of the policy is an intergovernmental agreement to a ten year shared expenditure plan (50 per cent Commonwealth government, matched by the State and Territory governments in proportion to their percentages of the national school enrolment totals). The plan aims for 60 per cent of all students at year 10 to be studying a priority language by the completion date of the policy.

This spending is on behalf of the teaching of four languages: Chinese, Japanese, Indonesian and Korean. Funding for the Strategy has been retained by the new Commonwealth government and announced to last until 2004. The four languages were selected on the basis of trade volume statistics, namely, the total financial value of the exchange of goods and services between Australia and the main foreign markets where these languages are spoken.

The figures are supplied by the Department of Foreign Affairs and Trade and the strategy expresses that its only basis for modification is any change in these figures as noted by the same Department. This is significant in that the capacity for modifying what is essentially a program for the teaching of languages in schools rests with a Commonwealth government department that has no relationship at all with schools.

The NALSAS approach to national language policy making is based on the notion that governments should be assertive, should set prescriptive targets and should impose what they consider to be 'national priorities'. It adopts a rather non-problematical notion of the national interest and believes that such an entity is either in inevitable conflict with community interests, or at least that other interests deflect attention from the pre-eminently important national interest. What the national interest is at any one time is to be determined by certain public elites who are engaged professionally in national representation in trade and geopolitical strategy.

Even within its own logic, NALSAS has problems. It has been criticised for being impractical in its targets and assumptions. The National Board of Employment, Education and Training (NBEET) review of the implementability of this and other language policies delivered a trenchant criticism of language policy made through trade and foreign affairs related considerations. Arguing that those considerations had little sense of the concrete constraints and practical realities in schools and teaching, the report went on to describe NALSAS as consisting of 'rhetorical enthusiasms' (NBEET, 1996). 
Research in sociolinguistics (study of language in social context) has provided strong evidence about how formal education in languages needs to work hand in hand with outside-of-school communicative realities for best outcomes (Baetens Beardsmore, 1992 and 1993; Cummins, 1996). Languages are best learned (and retained) when the domains of real communicative use (the networks of community institutions and settings and culture - the ecologies) that sustain languages are built upon and extended. This principle would indicate that foreign language teaching (teaching and learning of languages not spoken in the daily environments in which learners live) is less likely to be successful than programs in which the setting of the language study makes it available for informal acquisition. As a principle for acquisition planning this insight is important since pedagogical compensations for wider environmental constraints would need to be provided to enhance the chances of successful learning. A further implication would be that community based Asian languages could be profitably encouraged and community language maintenance supported.

Beyond these considerations another result of the directive top-down policy style enshrined by NALSAS, and its restricted remit, is that NALSAS excludes important potential beneficiaries from the increased funding it supplies. Excluded from any benefit are:

- all Asian languages other than the four it declares to be of priority concern;

- all Australian community contexts for all Asian languages (including any Australian context for the privileged four); and

- all 'non-Asian' languages.

Specifically excluded therefore are, for example:

- Vietnamese, Hindi, Arabic, Tamil, Filipino;

- all Australian community and institutional contexts or settings (that is, all Australian language and culture ecologies) for Chinese, Japanese, Indonesian and Korean; and

- all other languages (and their Australian ecologies), for example Spanish, Turkish, French, German and Swahili, have no place at all in the only national language policy vision that the Commonwealth and State governments have promulgated in the last decade.

These exclusions reinforce a pattern of selecting and prioritising shared with ALLP, but different from NPL. This pattern is one of favouring or distancing the spoken language diversity of Australia from shaping the content of language policy. The ideological frames of the NPL, the ALLP and NALSAS have tended towards selections from several binary alternatives:

- Multilingualism: Resource or Problem?

- Multiculturalism: a basis for Globalisation Policies or a Handicap?

- Motivation: Human Rights or Human Capital? 
- National Interest: Collaboratively Negotiated or Elite Determined?

- Community Language Ecologies: regarded Positively or Negatively?

- International Orientation: Global or Asian?

In each case, the first choice construes domestic multilingualism as a resource rather than as a problem. That choice bases language policy on a premise of mastery of standard forms and literate competence in spoken community languages rather than stressing the obstacle that the maintenance of such languages poses for the acquisition of English literacy by their learners.

A related, but more broadly cultural, consequence flows from preferring to see domestic multiculturalism as a kind of local instance of the intellectual and cultural challenges from globalisation (Cope and Kalantzis, 1997).

Similar consequences also occur when the overarching goal of languages policy is seen as containing a human rights perspective (Smolicz, 1994; Miller, 1999) rather than as an element of national human capital. Radically different notions of what is the priority concern and the dominant understanding of the purpose of policy results from this choice (Freebody, 1997; Lo Bianco, 1999a).

If community voices and interests are engaged in shaping national language policy altered notions of the national interest also emerge; ones which relate Australia to a global set of markets rather than regional Asian ones principally driven by current trade volume relationships. In this way the maintenance of Australian ecologies of languages (local environments in which minority languages can be sustained across generations, with the complementary acquisition of English) comes to assume a central, rather than a marginal, place in public policy.

Recent policies have turned away from making multiculturalism a basis for language policy. In this respect they reveal a significant gap between policy makers' sense of priorities and those of the wider community. Many opinion surveys conducted in the $1990 \mathrm{~s}$ indicate that public interest in diversity, languages and a plural notion of the Australian polity is buoyant. Several of those surveys, for example found that most Australians, in most age groups, imagine a multicultural and plurilingual Australian identity. 'Australian schools and higher education institutions still teach more languages, and Australian examination systems still accredit more languages, than in almost any other country in the world. Australian academics and researchers are still invited in greatly disproportionate numbers to advise international agencies and foreign governments about the social and policy consequences of multilingualism.

\footnotetext{
${ }^{1}$ Saulwick Poll, The Age, 31 May, 1994 (65 per cent of respondents felt that Australia was a 'better place' due to the diverse origins of its population); The Age Poll, 19 June, 1996 (61 per cent of respondents agreed with the policy of multiculturalism); The Sydney Morning Herald Poll 5 November, 1996 (70 per cent of respondents disagreed that the policy of multiculturalism should be abolished); Newspoll, The Australian 3 May, 1997 (78 per cent of respondents stated that multiculturalism had been good).
} 
In short there is no one-to-one correlation between Commonwealth policy developments and the actual language use patterns of languages in Australia nor of the public priorities for language choices. This is partly because language policies have ambiguous effects and partly because the Commonwealth does not have a jurisdictional monopoly on the contexts where language can be influenced. For example, States jealously protect their constitutional control of education. But there is another reason. The wider Australian community does not seem to share the Commonwealth government's view about what the national interest is. The community seems to prefer language and cultural policies that are more wideranging and inclusive than successive Commonwealth governments have adopted.

Language restrictionism, from the ALLP through NALSAS, is connected directly with, and has made possible, several recent negative language developments. What comes to mind here is the Northern Territory Government's planned removal of funding from Aboriginal bilingual programs. While many improvements to bilingual programs are needed these should be in the context of a truly bilingual project that aims to achieve mastery of both English and an Aboriginal language. However, the Commonwealth and State governments appear to have decided that English literacy is the sole worthwhile objective for indigenous bilingual education (Lo Bianco, 1999b; Miller, 1999; Nichols, 1999; Yunupingu, 1999).

Other indicators of a more restrictive language policy are apparent. There is continuing pressure to reduce the range and number of languages offered in Australian schools and several Universities have cut back strongly on the number of languages that they offer and more cuts are threatened (NLLIA, 1995). Other Universities teach non-English literature programs in English partly because learners are not permitted sufficient time to read originals (Carroli, Hillman and Maurer, 1999). The teaching of English as a second language to immigrant pupils across the country is taking second place to the prevailing concern for general literacy standards (McKay, 1998a; 1998b). Policy on English for immigrants is generally considered to have 'lost its way' (Cahill, 1996).

\section{Conclusion}

Multilingualism as a policy objective, with English as the common language, can draw on multiple justifications including issues of social equity; economic benefit and efficiency; cultural and intellectual enrichment, all of which are associated with the acquisition and use of more than one language. A language ecology in which foreign, community and traditional languages can develop alongside English in a stable and mutually reinforcing manner provides a strong foundation for successful learning of languages. The quality and sophistication of the national culture that would result, the diversified international connections that multilingualism makes possible and the intellectual and community enrichment that it uniquely can produce are subtle dimensions to policy that elude direct planning. Apart from the cultural arguments, the globalising economic environment adds commercial interest to language learning relevant for 
Australia's Asian context, and its ongoing connections with Europe and growing connections with other parts of the world.

The complexity of language, however, makes it a very difficult object of policy. It is an interesting coincidence of history that in 1999 Australia celebrated the fiftieth anniversary of Australian citizenship and the fiftieth anniversary of the founding of the Adult Migrant English Program. This Commonwealth government initiative was one of the policy pillars with which the post war governments were able to assuage public concern about new arrivals and about 'difference' (Martin, 1999: 5).

In addition the vast power of English as an international language of commerce is such that exclusively trade-based arguments for language policy are unpersuasive. If what is sacrificed is a wider commitment to language pluralism then the efficiency of concentrating on the acquisition of skills directly related to trade among new learners would seem to be questionable.

The complex conjunction of domestic multilingualism and economic regionalisation and globalisation makes it useful for Australia to take decisive steps to influence and shape the language and literacy capabilities of its citizens. Since language learning is a slow and complex process it is desirable to commence programs early in primary education aiming to achieve early bilingual awareness and if possible proficiency. This will probably dictate a choice of languages that are cognates of English and are written with the Roman orthography. In secondary schools and at higher education levels, the fostering of other languages with wider commercial and regional strategic interest would be desirable.

For minorities the cultivation of their children's potential precocious bilingualism is highly desirable. This is because the 'rates of return' will be greater. Cantonese speaking Australian children are, on average, more likely to acquire Modern Standard Chinese better and faster than raw beginners. However there is a deeper reason. The community needs encouragement and support to resist the pressure towards English-only. Our community has available to it a diminishing resource of multilingualism. Every year it becomes more tenuous as more and more young people prefer to concentrate on more professionally oriented courses of study and the retention of home-language skills becomes more difficult.

The multiple associations of language mean that when language enters the policy realm it is unlikely that a focus on the most narrow and forced utilitarian bases can be sustained.

\section{References}

Baetens Beardsmore, H. (1992), 'The European School Model', pp. 121-154 in Multilingual Matters 92: European Models of Bilingual Education, Multilingual Matters, Clevedon.

Baetens Beardsmore, H. (1993), 'European Models of Bilingual Education: Practice, Theory and Development', Joumal of Multilingual and Multicultural Development 14(1) $\&(2): 103-120$. 
Byrnes, M. (1994), Australia and the Asia Game, Allen and Unwin, Sydney.

Cahill, D. (1996), Immigration and Schooling in the 1990s, Bureau of Immigration, Multicultural and Population Research, Department of Immigration and Multicultural Affairs, Canberra.

Carroli, P., R. Hillman and L. Maurer (1999), 'Australian Perspectives on (Inter) National European Narratives', pp 155-167 in Lo Bianco, J., A. Liddicoat and C. Crozet (eds), Striving for the Third Place, Intercultural Competence through Language Education, Language Australia, Melbourne.

Clyne, M. (1991a), Community Languages: The Australian Experience, Cambridge University Press, Cambridge.

Clyne, M. (1991b), 'Australia's Language Policies: Are We Going Backwards?' Current Affairs Bulletin 68(6):13-20.

COAG (Council of Australian Governments) (1994), Asian Languages and Australia's Economic Future, A Report Prepared for the Council of Australian Governments on a Proposed National Asian Languages/Studies Strategy for Australian Schools, Queensland Government Printer, Brisbane.

Cooper, R. (1989), Language Planning and Social Change, Cambridge University Press, Cambridge.

Cope, B., and M. Kalantzis (1997), Productive Diversity: A New Australian Model for Work and Management, Pluto Press, Sydney.

Cummins, J. (1996), Negotiating Identities: Education for Empowerment in a Diverse Society, California Association for Bilingual Education, Los Angeles.

Department of Employment, Education and Training (DEET) (1991), Australia's Language: The Australian Language and Literacy Policy, vols I and II. (Released by J. Dawkins, Minister for Employment Education and Training), Canberra.

Djite, P. (1994), From Language Policy to Language Planning: An Overview of Languages other than English in Australian Education, National Languages and Literacy Institute of Australia, Melbourne.

Edwards, J. (1994), Multilingualism, Routledge, London.

Freebody, P. (1997), 'Assessment as Communal Versus Punitive Practice: Six New Literacy Crises for Australia', Literacy and Numeracy Studies 7:5-17.

Freebody, P. (1998), 'Findings from the Literacy Scandal: Disconcert, Tremulousness, and Meditation', English in Australia 122:10-14.

Galbally Report (Review of Post-Arrival Services and Programs to Migrants, F. Galbally, Chairman) (1978), Migrant Services and Programs, AGPS, Canberra. 
Herriman, M. (1996), 'Language Policy in Australia', pp. 35-62, in M. Herriman and B. Burnaby (eds), Language Policy in English-Dominant Countries, Multilingual Matters, Clevedon.

Ingram, D. (1994), 'Language Policy in Australia in the 1990s', pp. 69-111 in R. Lambert (ed.) Language Planning Around the World: Contexts and Systemic Change, National Foreign Language Center, Johns Hopkins University, Washington DC.

Irwin, H. (1996), Communicating With Asia: Understanding People and Customs, Allen and Unwin, Sydney.

Kaplan, R. and H. Widdowson (1992), 'Applied Linguistics: An Overview', pp. 76-80 in International Encyclopedia of Linguistics, vol. 1, Oxford University Press, Oxford.

Lo Bianco, J. (1987), National Policy on Languages, AGPS, Canberra.

Lo Bianco, J. (1990), 'Making Language Policy: Australia's Experience', pp. 47-79 in $R$. Baldauf Jr. and A. Luke (eds), Language Planning and Education in Australasia and the Pacific, Multilingual Matters, Clevedon.

Lo Bianco, J. (1996), 'Asia-literacy, Australian Studies and a Plural Nation: Articulating Perspectives on Social Education of Young Australians', Curriculum Perspectives 16(3):55-59.

Lo Bianco, J. (1999a), 'Globalisation: Frame Word for Education and Training, Human Capital and Human Development/Rights', Language Australia Research Policy and Practice Papers No. 1, Melbourne.

Lo Bianco, J. (1999b), 'Words of Power: Talking Bilingual Education and ESL into English Literacy', Prospect 14 (2):40-52.

Lo Bianco, J. (2000), 'Language Policies: State Texts for Silencing and Giving Voice', forthcoming in P. Freebody, S. Muspratt, and B Dwyer (eds), Difference, Silence and Textual Practice: Studies in Critical Literacy, Hampton Press, Creskille, New Jersey.

Martin, S. (1999), New Life, New Language: The History of the Adult Migrant English Program, National Centre for English Language Teaching and Research, Macquarie University.

McKay, P. (1998a), 'Discriminatory Features for ESL Learners in the Literacy Benchmarks', Australian Council of TESOL Associations, Melbourne, (ACTA Background Papers No. 2).

McKay, P. (1998b), 'The Literacy Benchmarks and ESL', Australian Council of TESOL Associations, Melbourne, (ACTA Background Papers No. 3).

Miller, C. (1999), 'Bilingual Education in the Northern Territory: The Possibility of Recourse?', Australian Language Matters 7(3):6. 
Moore, H. (1996), 'Language Policies as Virtual Realities: Two Australian Examples', TESOL Quarterly 30(1):473-497.

NBEET (National Board of Employment, Education and Training) (1996), Language Teachers: The Pivot of Policy, The Supply and Quality of Teachers of Languages other than English, National Board of Employment, Education and Training, Canberra.

Nichols, C. (1999) 'Let's Stop Pushing Australia's Indigenous Languages Aside', Australian Language Matters 7(3):5.

NLLIA (National Languages and Literacy Institute of Australia) (1995), The Viability of Low Candidature LOTE Courses in Universities, NLLIA and DEET, AGPS, Canberra.

Ozolins, U. (1993), The Politics of Language in Australia, Cambridge University Press, Cambridge.

OMA (1989), National Agenda for a Multicultural Australia: Sharing our Future, Office of Multicultural Affairs (Department of Prime Minister and Cabinet), AGPS, Canberra.

Ruiz, R. (1984), 'Orientations in Language Planning', National Association for Bilingual Education Journal 8:15-34.

Sheridan, G. (ed.) (1995), Living with Dragons: Australia Confronts its Asian Destiny, Allen and Unwin, Sydney.

Smolicz, J. (1994), 'Australia's Language Policies and Minority Rights: A Core Value Perspective', pp. 235-253, in T. Skutnab-Kangas and R. Phillipson (eds), Linguistic Human Rights: Overcoming Linguistic Discrimination, Mouton de Gruyter, Berlin.

Selleck, R. (1980), 'The Trouble with my Looking Glass: A Study of the Attitude of Australians to Germans during the Great War', Joumal of Australian Studies 6:1-25.

Yunupingu, M. (1999), 'Double Power', pp. 1-4 in P. Wignell (ed.), Double Power: English Literacy and Indigenous Education, Language Australia, Melbourne.

I am grateful to the editors and two anonymous referees for useful comments on an earlier draft of this paper. 